\title{
REPRESENTASI YOGYAKARTA DALAM FILM ADA APA DENGAN CINTA 2
}

\author{
Evi Rosfiantika1 ${ }^{1}$, Jimi N. Mahameruaji ${ }^{1}$, Rangga Saptya Mohamad Permana ${ }^{1}$ \\ ${ }^{1}$ Universitas Padjadjaran
}

\begin{abstract}
ABSTRAK
Yogyakarta menjadi setting tempat dalam film Ada Apa Dengan Cinta 2. AADC 2 memberikan nuansa seni dan romantisme dalam dialog dan cerita Film tersebut, Yogyakarta sebagai kota yang memiliki kebudayaan yang khas direpresentasikan dalam aktifitas seni, kehidupan keseharian dan nilai-nilai yang ada dalam masyarakatnya. Film termasuk ke dalam salah satu media massa yang bisa merepresentasikan nilai-nilai budaya dan identitas bangsa. Bertujuan untuk mengetahui representasi Yogyakarta dalam film Ada Apa Dengan Cinta 2. Metode yang digunakan adalah semiotik. Berisi pengamatan dan analisis simbol-simbol yang muncul mengenai Yogyakarta dalam film $A A D C$ 2. Untuk triangulasi dilakukan studi pustaka dan wawancara.Hasilnya menjadi acuan/bahan/materi dari beberapa mata kuliah Program Studi Televisi dan Film yaitu Sosial Budaya Indonesia, Produksi Film, dan Kajian Film.
\end{abstract}

Kata-kata Kunci: Representasi, Budaya, Yogyakarta, Film, Semiotik

\section{REPRESENTATION OF YOGYAKARTA IN “ADA APA DENGAN CINTA 2" MOVIE}

\begin{abstract}
'Ada Apa Dengan Cinta 2' movie which made Yogyakarta as its setting background succeeded in giving an art and romantic nuance in the film. Yogyakarta is one of the city that has a distinctive culture which is represented through the values, art, and daily life activities existing in the community. Films as one of the mass media can represent the cultural values and by far the national identity. Its purpose is to know the representation of Yogyakarta in the movie Ada ApaDenganCinta 2. The method used in this research is semiotic. It contains observations and analysis of symbols that appear about Yogyakarta in the movie AADC 2. The triangulation is conducted through literature studies and interviews. The result is a reference/materials for several subjects in the Television and Film Studies Program, such as Indonesian Social Culture, Film Production, and Film Review.
\end{abstract}

Keywords: Representation, Culture, Yogyakarta, Film, Semiotics

Korespondensi: Evi Rosfiantika, S.Pd., M.Si. Universitas Padjadjaran. Jl. Raya Bandung-Sumedang Km. 21 Sumedang 45363. Email: evi_rosfiantika@yahoo.co.id

Submitted: November $4^{\text {th }}, 2016$, Revision: January $4^{\text {th }}, 2017$, Accepted: March $4^{\text {th }}, 2017$

ISSN: 2548-687X (cetak), ISSN: 2549-0087 (online)

http://jurnal.unpad.ac.id/protvf 


\section{PENDAHULUAN}

Yogyakarta menjadi setting tempat dalam salah satu film Indonesia, yaitu Ada Apa Dengan Cinta 2 (AADC 2). yang disutradarai oleh Riri Riza, film ini merupakan sekuel dari Film $A A D C$ pertama yang dirilis pada tahun 2002 karena Yogyakarta merupakan salah satu daerah istimewa di Indonesia yang menyimpan kekayaan budaya, kreativitas para penduduknya, sejarah juga tempat-tempat berkumpul seniman, semua hal tersebut menjadi menarik untuk ditampilkan dalam sebuah film.

Sutradara $A A D C 2$ yaitu Riri Riza dan produser Mira Lesmana tertarik memilih Yogyakarta, yang merupakan sebuah Kotayang memiliki unsur modernisasi dan tradisional dalam kehidupan dan perkembangan budaya masyarakatnya sebagai latar dalam pertemuan tokoh utamanya.

Seniman musik aliran modern tetapi tetap menggunakan bahasa daerah dalam lagunya tampil dalam film ini yaitu anggota Yogja Hip Hop Foundation, Marzuki Muhammad atau sering disebut Kill The DJ menyanyikan lagu berjudulRaminggir Tabrak.

Tempat-tempat yang menjadi setting dalam perjalanan tokoh utamanya di Yogyakarta memberikan nuansa seni dan budaya misalnya seniman kopi yang ada di Klinik Kopi dan Eko Nugroho yang menampilkan seni instalasinya dalam sebuah pameran.

Kelompok teater khas Yogyakarta yaitu salah satunya teater boneka Pappermoon Puppet menampilkan sebuah pertunjukan berjudul Secangkir Kopi dari Playa bercerita perpisahan sepasang kekasih karena masalah politik memberikan gambaran gaya hidup masyarakat Yogyakarta yang menyukai pertunjukan seni sebagai tempat berkumpul para seniman.

Berdasarkan pemaparan di atas, sebuah film memiliki hubungan erat dengan budaya. Memahami film adalah memahami cerminan kondisi masyarakat, nilai dan norma pada saat film tersebut diproduksi. Yogyakarta menjadi latar tempat dalam pertemuan tokoh utamanya dalam film AADC 2 yang memberikan penguatan karakter mereka yang membaur dan terintegrasi dalam sebuah lingkungan seni dan budaya yang khas.

\section{Representasi}

Representasi merupakan kegunaan dari tanda. Danesi (dalam Wibowo, 2011: 122) mendefinisikannya sebagai berikut:

"Proses merekam ide, pengetahuan atau pesan dalam beberapa cara fisik disebut representasi. Ini dapat didefinisikan lebih tepat sebagai keguanaan dari tanda yaitu untuk menyambungkan, melukiskan, meniru sesuatu yang dirasa, dimengerti, diimajinasikan, atau dirasakan dalam beberapa bentuk fisik...... Dapat dikarakterisasikan sebagai proses konstruksi bentuk $\mathrm{X}$ untuk menimbulkan perhatian terhadap sesuatu yang ada secara material atau konseptual, yaitu Y, atau dalam bentuk yang spesifik $\mathrm{Y}, \mathrm{X}=\mathrm{Y}$.”

Danesi mencontohkan representasi dengan sebuah konstruksi $\mathrm{X}$ yang berarti mewakili atau memberikan suatu bentuk terhadap konsep tentang Y. Pierce menyebut bentuk fisik aktual, 
$\mathrm{X}, \quad$ sebagai representamen (yang merepresentasikan); sedangkan Y dirujuknya sebagai objek representasi; dan menyebut makna-makna yang diuraikan dari representasi $(\mathrm{X}=\mathrm{Y})$ sebagai interpretan.

Representasi merupakan aplikasi atau penggambaran makna yag abstrak menjadi tindakan yang riil. Stuart Hall memetakan sistem representasi ke dalam dua bagian utama, yakni mental representation dan bahasa. Mental representation bersifat subjektif, indivisual; masing-masing memiliki perbedaan dalam mengorganisasikan dan merumuskan konsepkonsep sekaligus menetapkan hubungan antara semua itu.

Bahasa menjadi bagian sistem representasi karena pertukaran makna tidak mungkin terjadi ketika tidak ada akses terhadap bahasa bersama. Dengan kata lain, bahasa merupakan media pengantar dalam mengekspresikan makna yang telah diidentifikasi dari sebuah konsep. Media sebagai suatu teks banyak memuat representasi pada isinya. Representasi dalam media menunjuk kepada seseorang atau kelompok, gagasan atau pendapat tertentu ditampilkan pada pemberitaan (Eriyanto, 2011: 13).

Representasi bekerja dalam hubungan tanda dan makna. Namun makna dari realitas dapat berubah-ubah akibat dari representasi yang berubah pula. Ada pelibatan negosiasi dalam pembentukan makna tersebut, dimana negosiasi tersebut mendapat kesepakatan bersama dan adanya input dari pengalaman subjektif dari individu.

Proses representasi merupakan proses yang dinamis seiring dengan kemampuan intelektual dan kebutuhan dari para pengguna tanda. Representasi juga merupakan suatu bentuk konstruksi. Seiring bertumbuhnya kosntruksi pemikiran manusia, maka akan menghasilkan konstruksi representasi yang baru, dengan memanfaatkan tanda-tanda baru yang direkam oleh intelektual individu. Representasi makna diproduksi dan dikonstruksi melalui proses penandaan, penyeleksian, dan pengaktegorikasian sehingga makna tersebut bisa berarti sesuatu bagi pengguna dan konsumen tanda.

Representasi merupakan proses penyeleksian suatu realitas tertentu dan mengabaikan realitas yang lain. Seperti yang diungkapkan oleh Croteau dan Hoynes (dalam Wibowo, 2011: 123),

Dalam representasi di media, tanda yang digunakan untuk melakukan representasi harus melalui proses seleksi. Tanda-tanda yang digunakan mewakili kepentingan-kepentingan yang mewakili ideologis dari kelompok tertentu sementara tanda yang lainnya diabaikan.

Representasi Yogyakarta sebagai kota perjuangan bangsa Indonesia dari jaman penjajahan Belanda, Jepang, dan jaman perjuangan mempertahankan kemerdekaan terdapat dibeberapa sudut. Yogyakarta juga menjadi pusat kerajaan Mataram (Islam) peninggalan-peninggalan budaya bernilai tinggi semasa kerajaan-kerajaan tersebut sampai saat ini masih ada.

Yogyakarta sebagai kota seni dan budaya direpresentasikan dalam kehidupan para seniman yang banyak menampilkan 
pertunjukan dan pameran seni dalam kegiatan masyarakatnya.

\section{Profil Film Ada Apa Dengan Cinta 2 (AADC}

$$
\text { 2) }{ }^{1}
$$

Produser Mira Lesmana

Sutradara Riri Riza

Penulis Mira Lesmana, Prima Rusdi

Skenario

Pemain Dian Sastrowardoyo, Nicholas Saputra, Adinia Wirasti, Titi Kamal, Sissy Priscillia, Dennis Adhiswara, Christian Sugiono, Ario Bayu

Jumlah $\quad 3.658 .000$

Penonton

Genre Film

Drama, Romance

Tanggal

Tayang

Negara

Rumah

Produksi

Bahasa Film Indonesia

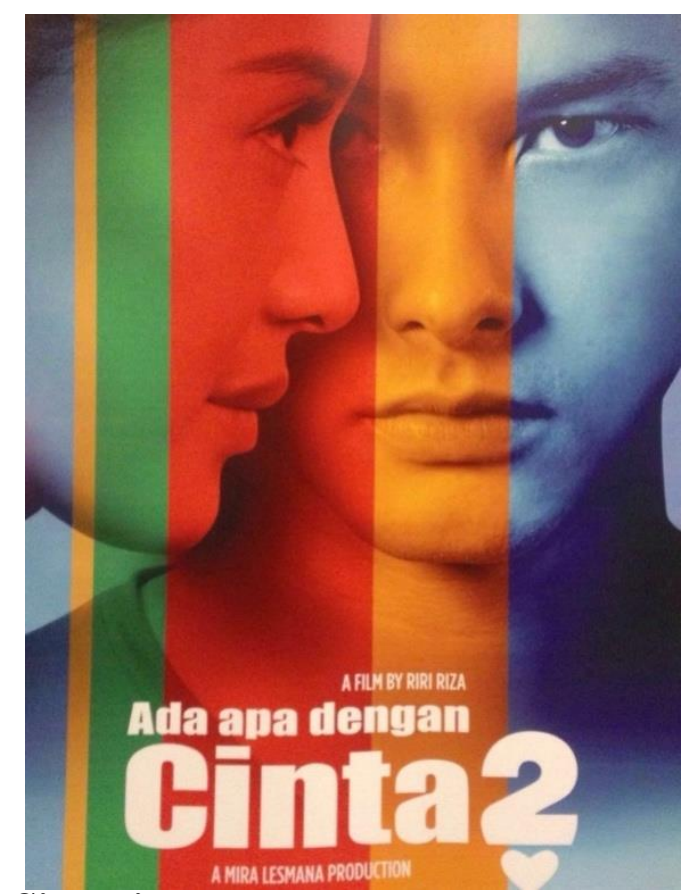

\section{Sinopsis}

28 April 2016 (Indonesia, Malaysia, Brunei Darussalam) Indonesia Legacy Pictures, Miles Films

Cinta dan Rangga berpisah setelah, Rangga pergi ke New York, mereka menjalani hubungan jarak jauh sampai dengan tahun 2006. Rangga memutuskan hubungan dengan cinta.
Cinta akhirnya akan bertunangan dengan lelaki lain, setelah 9 tahun perpisahan itu. Temanteman Cinta sudah memiliki kehidupan masingmasing. Milly sudah menikah dengan teman mereka semasa SMA dan akan memiliki anak. Sementara Maura sudah menikah dan memiliki seorang anak, Carmen mengalami masalah narkoba dan baru saja keluar dari panti rehabilitasi. Sementara Alyameninggal akibat kecelakaan.Setelah Carmen keluar dari panti rehabilitasi, mereka memutuskan liburan ke Yogya.

Rangga kembali ke Yogyakarta untuk menjenguk ibunya yang sedang sakit. Awalnya, hanya teman-teman Cinta yang melihat Rangga. Mereka bimbang akan memberitahu Cinta atau tidak. Akhirnya mereka memberitahu Cinta, yang awalnya menolak bertemu. Namun, didorong ingin mendapatkan kejelasan mengapa Rangga memutuskannya, akhirnya mereka bertemu. Perjalanan Cinta dan Rangga menjelaskan keadaan mereka masing-masing didalam perjalanan selama sehari semalam yang mengungkap masa lalu mereka. Ternyata, Rangga meninggalkan Cinta karena ia merasa tidak mampu membahagiakan Cinta. Dulu Ayahnya meminta ia segera lulus kuliah agar dapat menikah dengan Cinta. Tapi waktu itu ia kesulitan untuk menyelesaikan kuliah karena sambil bekerja. Ia merasa tidak mampu membahagiakan Cinta dan memutuskannya secara sepihak. Perjalanan mereka mengunjungi tempat-tempat menarik di Yogya, termasuk warung kopi indie. Film ini memang melibatkan

\footnotetext{
${ }^{1}$ http://movie.co.id/ada-apa-dengan-cinta-2/
} 
banyak seniman lokal. Setelah perjalanan mereka berakhir, Rangga menulis surat untuk Cinta. Di surat itu ada puisi dan perasaan Rangga yang masih mencintai Cinta. Cinta pergi menyusul Rangga ke New York dan Di akhir cerita, Rangga dan Cinta kembali ke Jakarta. Happy ending.

\section{Budaya}

Budaya dan unsur-unsur di dalamnya terikat oleh waktu dan bukan kuantitas yang statis. Budaya tetap berubah dan dinamis, seberapa lamban pun perubahan tersebut. Kelambanan dan kecepatan perubahannya bergantung pada seberapa jauh kekuatan budaya tersebut dan intensitas interaksinya dengan budaya lain. Suatu budaya yang lemah yang sering berhubungan dengan budaya lain yang kuat, maju dan dominan akan cepat berubah karena pengaruh budaya kedua. Contohnya saja budaya Indonesia yang cepat berubah karena dipengaruhi budaya Barat. Sebaliknya, komunitas budaya yang intensitas interaksinya sedikit dengan budaya luar akan lamban berubah, seperti ditunjukkan budaya suku Eskimo di Kutub Utara, suku Aborigin di Australia, dan suku Baduy (urang Kanekes) di Banten. Lengkapnya, budaya memiliki ciri-ciri sebagai berikut (Mulyana, 2008: 23):

1. Budaya buka bawaan, tetapi dipelajari.

2. Budaya dapat disampaikan dari orang ke orang, dari kelompok ke kelompok, dan dari generasi ke generasi.

3. Budaya berdasarkan simbol.

4. Budaya bersifat dinamis, suatu sistem yang terus berubah sepanjang waktu.
5. Budaya bersifat selektif, merepresentasikan pola-pola perilaku pengalaman manusia yang jumlahnya terbatas.

6. Berbagai unsur budaya saling berkaitan.

7. Etnosentrik (menganggap budaya sendiri sebagai yang terbaik atau standar untuk menilai budaya lain).

\section{Semiotika}

Film sebagai sistem konotasi atau ideologi, sehingga film apapun bisa diperlakukan sebagai mitos yang merujuk kepada fragmen ideologi tertentu (Barthes dalam Budiman, 28:2016).

Tanda-tanda visual dalam film dibedakan jadi dua tipe pesan yang terkandung dalam proses signifikasi citra (image). Pertama, citra sebagai pesan ikonik berupa adegan (scene), lanskap, atau realitas harfiah yang terekam, citra tersebut dibedakan dalam dua tataran yaitu pesan harfiah (ikonik tak-berkode) sebagai sebuah analogon itu sendiri yang berfungsi untuk menaturalkan pesan simbolik, dan pesan simbolik (ikonik berkode) merupakan tataran konotasi yang keberadaannya didasarkan atas kode budaya tertentu (Barthes dalam Budiman, 29:2016)

Semiotika secara etimologis berasal dari bahasa Yunani "semeion" yang berarti tanda. Dengan demikian, Semiotika adalah ilmu tanda. Tanda dalam Analisis Semiotika mempunyai peran yang sangat penting, karena tanpa tandatanda, pesan tidak akan tersampaikan. Tanda harus bisa menyajikan apa yang akan diungkapkan, merujuk kepada sesuatu atau konteks tertentu dan mewakili teks tersebut. Seorang ahli filsafat dan logika yaitu Charles Sanders Peirce (1839 - 1914) dan seorang ahli 
linguistik bernama Ferdinand de Saussure (1857

- 1913) merupakan tokoh penting dalam kajian semiotika modern. Menurut Peirce, logika harus digunakan untuk bernalar melalui tanda-tanda itu. Tanda memungkinkan manusia untuk berpikir, berhubungan dengan manusia lainnya dan memaknai apa yang terjadi di lingkungan sekitarnya.

Awal mula konsep semiotik diperkenalkan oleh Ferdinand de Saussure melalui dikotomi sistem tanda: signified dan signifier. Konsep ini melihat bahwa makna muncul ketika ada hubungan yang berasosiasi antara "yang ditandai" (signified) dan "yang menandai" (signifier). Tanda adalah kesatuan dari suatu bentuk penanda (signifier) dengan sebuah ide atau petanda (signified). Dengan kata lain, penanda penanda adalah "bunyi yang bermakna" atau "coretan yang bermakna". Jadi, penanda adalah aspek material dari bahasa yaitu apa yang dikatakan dan didengar dan apa yang ditulis atau dibaca. Jadi, petanda adalah aspek mental dari bahasa.

Beberapa rangkuman pembahasan semiotika antara lain meliputi:

1. Semiotika menaruh perhatian pada bagaimana makna dikonstruksi dan disampaikan melalui teks khususnya melalui narasi atau cerita.

2. Fokus perhatian semiotika adalah tanda yang terkandung dalam teks.

3. Mengingat tidak sesuatu pun mempunyai makna untuk dirinya sendiri, hubungan yang ada diantara tanda-tanda menjadi sangat penting, karena sebuah bahasa bisa dibuat analoginya dari penyususnan kata dan bahasa. Bahasa adalah sebuah institusi sosial yang menjelaskan bagaimana katakata yang dikombinasikan dan digunakan.

Semiotika adalah studi mengenai tanda (signs) dan simbol yang merupakan tradisi penting dalam pemikiran tradisi komunikasi. Tradisi semiotika mencakup teori utama mengenai bagaimana tanda mewakili objek, ide, situasi, keadaan, perasaan, dan sebagainya yang berada di luar diri.

\section{METODE PENELITIAN}

Data yang diteliti adalah scene-scene film AADC2 yang merepresetasikan Yogyakarta, data diolah melalui metode penelitian kualitatif. Pendekatan ini tidak mencoba menggeneralisasikan makna dari penelitian namun justru faktor kontekstual (perseorangan) yang menarik dari hasilnya (Moleong, 2000:4). Teks dalam film ini dipandang sebagai sarana sekaligus media melalui pendekatan paradigma kritis.

Menggunakan metode semiotika Roland Barthes yang secara umum dipahami sebagai ilmu tentang tanda. Ferdinant de Saussure sebagai "pencetus" pertama dalam konsepnya tentang tanda, yang merupakan kombinasi antara penanda dan petanda menegaskan bahwa hubungan antara penanda dan petanda ini sifatnya arbitrer. Konsep ini juga digunakan oleh Barthes dalam semiologinya mengenai tingkatan pemaknaan denotasi, konotasi / mitos dan mitis terhadap tanda.

\section{Denotasi}


ProTVF, Volume 1, Nomor, 1, Maret 2017, Hal. 47-60

Denotasi merupakan sistem signifikasi tingkat pertama, sementara konotasi merupakan tingkat kedua. Dalam hal ini denotasi justru lebih diasosiasikan dengan ketertutupan makna dan, dengan demikian, sensor atau represi politis. Sebagai reaksi yang paling ekstrem melawan keharfiahan denotasi yang bersifat opresif ini, Barthes mencoba menyingkirkan dan menolaknya. Baginya, yang ada hanyalah konotasi semata-mata. Penolakan ini mungkin terasa berlebihan, namun ia tetap berguna sebagai sebuah koreksi atas kepercayaan bahwa makna "harfiah" merupakan sesuatu yang bersifat alamiah (Budiman, 1999 : 22).

Makna denotasi pada dasarnya meliputi hal-hal yang ditunjuk oleh kata-kata. Analisis denotasi dalam penelitian ini merupakan pemaknaan tingkat pertama terhadap makna tanda. Barthes mendefinisikan denotasi sebagai makna paling nyata dari tanda dalam teks. Secara khusus denotasi dapat didefinisikan sebagai first order of signification terhadap sistem tanda yang terdiri dari penanda dan petanda.

Dalam menjelaskan sistematisasi dalam proses pemaknaan Barthes menyatakan bahwa kajian utama dari pemaknaan dua tahap ini terletak pada konotasi. Barthes menjelaskan bahwa signifikasi tahap pertama adalah hubungan antara signifier dan signified di dalam sebuah tanda terhadap realitas eksternal atau Barthes lebih suka menyebutnya makna yang paling nyata dalam sebuah tanda (Barthes dalam Sobur, 2001 : 128).

Makna denotasi bersifat langsung, yaitu makna khusus yang terdapat dalam sebuah tanda, dan pada intinya dapat disebut sebagai gambaran sebuah petanda (Berger, $2000: 55$ ). Berkaitan dengan hal tersebut, Chandler menerangkan:

"In semiotics, denotation and connotation are terms describing the relationship between the signifier and its signified, and an analytic distinction is made between two types of signifieds: a denotative signified and a connotative signified." ( Chandler, 1999 : 95)

Selanjutnya dapat dikatakan bahwa perbedaan denotasi dan konotasi terletak pada penandanya. Penanda denotasi menunjuk konsep mental dan apa yang dilakukan (aspek material) dari penanda denotasi. Sedangkan petanda konotasi lebih menunjuk pada adanya ciri tertentu yang oleh Barthes disebut sebagi fragmen ideologi (Barthes dalam Kurniawan, $2001: 68)$.

\section{Konotasi}

Konotasi mengacu pada makna yang menempel pada suatu kata karena sejarah pemakaiannya. di dalam semiologi Roland Barthes, terdapat dua jenis sistem signifikasi. Sistem pertama berada di dalam lapis denotasi, sedangkan sistem kedua di dalam lapis konotasi. Sebuah sistem konotasi adalah sistem yang lapis ekspresinya sendiri sudah berupa sistem penandaan: pada umumnya kasus-kasus konotasi terdiri dari sistem-sistem kompleks yang di dalamnya bahasa menjadi sistem pertama, misalnya seperti yang terlihat pada sastra.

Konotasi adalah sistem yang tersendiri disusun oleh penanda-penanda serta proses 
yang memadukan keduanya (signifikasi).

Penanda-penanda konotasi - disebut konotator

- terbentuk oleh tanda-tanda (kesatuan antara signifier dan signified) dari sistem pertama, sistem denotasi. Sementara itu, penandapetanda konotasi, yang sekaligus berkarakter general, global, dan tersebar, merupakan fragmen ideologi (Budiman, 1999 : 66).

Menurut makna leksikal konotasi dibedakan dengan denotasi. Secara semiotik, konotasi adalah sistem semiotik tingkat kedua yang dibangun di atas sistem semiotik tingkat pertama (denotasi) dengan menggunakan makna (meaning atau signification) sistem tingkat pertama menjadi Expression (atau signifier) (Sunardi, 2002 : 85).

\begin{tabular}{|c|c|c|}
\hline \multicolumn{2}{|c|}{ Expression } & Content \\
\hline Expression & Content & \\
\hline \multicolumn{2}{|c|}{ Konotasi } & \\
\hline
\end{tabular}

Skema 3.2 Konotasi

Sumber: Sunardi, ST., Semiotika Negativa, 2002

Dalam analisis semiotik, istilah signification biasanya hanya dipakai untuk sistem tanda tingkat kedua, karena pada tingkat ini tanda mencapai kata. Pada tingkat ini kita menghubungkan tingkat signifier dan signified sesuai dengan kondisi atau pengalaman kita; jadi, melibatkan subyektivitas kita sebagai audiens atau pemakai.

Konotasi mempunyai makna yang subyektif atau paling tidak intersubyektif (Sobur, 2001 : 128). Hal ini disebabkan oleh konsep penanda dan petanda konotasi menghasilkan makna mengenai "bagaimana" objek digambarkan, atau dengan kata lain denotasi adalah apa yang digambarkan tanda terhadap sebuah objek; sedangkan konotasi adalah bagaimana menggambarkannya, sehingga dikatakan konotasi bekerja dalam tingkat subyektif.

Konotasi adalah istilah yang digunakan Barthes untuk menunjukkan signifikasi tahap kedua. Yaitu pemaknaan terhadap sistem tanda makna yang di dalamnya melibatkan unsur sosiokultural dan asosiasi personal (ideologi, emosional) dari interpreter. Konotasi menempatkan tanda denotasi sebagai penanda terhadap petanda/signified baru sehingga melahirkan makna konotasi (second order of signification). Atau dengan kata lain penanda dalam pemaknaan konotasi terbentuk melalui tanda denotasi yang digabungkan dengan petanda baru/tambahan. Sehingga dapat dikatakan bahwa tanda denotasi akan sangat menentukan signifikasi selanjutnya/ konotasi (Chandler, 1999 : 98).

\section{Mitos}

Pada sistem pemaknaan kedua (konotasi) yang berkaitan dengan isi (content), tanda bekerja melalui mitos. Mitos dilihat sebagai produk kelas sosial yang sudah mempunyai suatu dominasi. Dengan kata lain, mitos menjelaskan atau memahami budaya dominan beberapa aspek realitas atau gejala alam dalam masyarakat. Dalam pandangan Barthes mitos dipahami sebagai ideologi dominan yang dimiliki manusia sepanjang hidupnya (Barthes dalam Chandler, 1999 : 99).

Chandler menerangkan bahwa petanda mitos yang terdapat dalam konotasi secara 
ProTVF, Volume 1, Nomor, 1, Maret 2017, Hal. 47-60

khusus masih bersifat expresive values, sehingga pada gilirannya expresive value ini akan berkembang menjadi ideologi pada sistem/ tingkat pemaknaan ketiga (mythic level) (Chandler,1999 : 99). Barthes menerangkan mengenai mitos dalam pemaknaan konotasi:

Myth is defined by its intention more than by its literal sense. In spite of this, its intention is somehow frozen, purified, eternalized, made by absent by this literal sense. This constituent ambiguity has two consequences for the signification, which henceforth appears both like a notification and like a statement of fact. (Barthes dalam Chandler, 1999 : 100)

Mitos adalah salah satu jenis semiotik tingkat kedua. Barthes mendefinisikannya sebagai "a type of speech". Mitos digunakan untuk mendistorsi atau mendeformasi signification dari sistem tanda semiotik tingkat pertama (Sunardi, 2002 : 86).

\begin{tabular}{|c|c|}
\hline 1. Signifier & 2. Signified \\
\hline \multicolumn{2}{|c|}{ 3. Sign (Meaning) } \\
\hline (I. SIGNIFIER) & (II. SIGNIFIED) \\
FORM & CONCEPT \\
\hline \multicolumn{2}{|c|}{ (III. SIGN) SIGNIFICATION } \\
\hline
\end{tabular}

Skema 3.3 Sistem Mitos

Sumber: S.T. Sunardi Semiotika Negativa, 2002

Dari skema diatas dapat dilihat bahwa, mitos atau sistem mitis dibuat dengan menggunakan sistem semiotik tingkat pertama sebagai signifier bagi sistem semiotik tingkat kedua. Signifier baru ini disebut form dan signified disebut concept. Hubungan antara form dan concept disebut signification atau mitos itu sendiri.
Menurut antropolog struktural LeviStrauss, mitos merupakan bagian dari bahasa yang substansinya tidak terletak pada gaya, irama, ataupun sintaksis, melainkan pada cerita yang diungkapkannya (Budiman, 1999 : 75). Fungsi mitos terletak pada suatu tataran khusus yang di dalamnya makna-makna melepaskan diri dari landasan yang semata-mata kebahasaan.

Myth is language, functioning on an especially high level where meaning succeeds practically at "taking off" fromm the linguistic ground on which it keeps on rolling. (Ahimsa-Putra, $2001: 85$ ).

Levi-Strauss menetapkan tiga landasan analisis struktural terhadap mitos sebagai berikut. Pertama, bahwa jika memang mitos dipandang sebagai sesuatu yang bermakna, maka makna ini tidaklah terdapat pada unsurunsur yang berdiri sendiri, yang terpisah satu dengan yang lain, tetapi pada cara unsur-unsur tersebut dikombinasikan satu dengan yang lain. Cara mengkombinasikan unsur-unsur mitos ini yang menjadi tempat bersemayamnya makna. Kedua, walaupun mitos termasuk dalam kategori 'bahasa' mitos memperlihatkan ciriciri tertentu yang lain lagi. Ketiga, ciri-ciri ini dapat kita temukan bukan pada tingkat bahasa itu sendiri tapi di atasnya.

Unit-unit terkecil mitos yaitu ceriteme, adalah kalimat-kalimat atau kata-kata yang menunjukkan relasi tertentu atau mempunyai makna tertentu. Sebuah ceriteme dapat dikatakan sebagai sebuah simbol, karena dia memiliki makna referential (acuan), tetapi di lain pihak cerita juga dapat ditanggapi sebagai 
sebuah tanda, yang mempunyai 'nilai' (value) dalam konteks tertentu.

\section{HASIL DAN PEMBAHASAN}

\section{Identifikasi Umum Temuan Data}

Film ini menceritakan tentang kisah cinta antara cinta dan Rangga yang terpisah selama empat belas tahun, kemudian bertemu kembali di Yogyakarta. mereka menghadapi konflik yang harus diselesaikan bersama. Banyak perubahan dalam hidupnya tetapi cinta yang kuat dan usaha mereka untuk menyelesaikan konflik tersebut yang membuat mereka kembali bersama. Film bergenre melodrama sering memberikan penonton adegan berkesan dan tak terlupakan. Istilah "melodrama" mengacu pada tiga kategori: mode, permainan teater, dan genre film. (Friedman, dkk.; 2014: 81)

Setting film 70 persen ada di Yogyakarta, hal tersebut membuat Yogyakarta menjadi tempat yang bisamemperkuat suasana emosional karakter dan plot. Setting Yogyakarta mempunyai hubungan dengan karakter tokoh utama, beberapa setting menjadi simbolik dalam menampilkan representasi Yogyakarta sebagai kota seni.

\section{Makna Denotasi, Konotasi dan Mitos yang} merepresentasikan Yogyakarta sebagai kota seni dan budaya

Untuk menjelaskan fokus masalah dalam penelitian ini, maka beberapa scene dibawah ini harus dianalisis sesuai dengan model analisis semiotik yang dipakai yaitu model semiotik Roland Barthes, sebagai berikut:

\section{Scene}

Adegan pertama yang dipilihadalahtempat hiburan yang ada di Yogyakarta menampilkan pentas musik.

\begin{tabular}{|c|c|c|}
\hline Visual & Dialog/Audio & Type of Shot \\
\hline 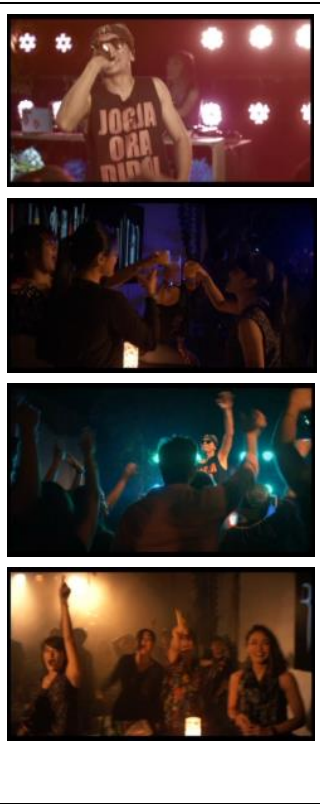 & $\begin{array}{l}\text { Tidak ada } \\
\text { dialog } \\
\text { Kill The DJ. } \\
\text { Marzuki } \\
\text { tampil } \\
\text { menyanyikan } \\
\text { lagunya } \\
\text { Raminggir } \\
\text { Tabrak. }\end{array}$ & $\begin{array}{l}\text { Medium Shot, } \\
\text { One shot } \\
\text { Memperlihatkan } \\
\text { pinggang keatas } \\
\text { dari subjek } \\
\text { Medium Shot, } \\
\text { Group Shot } \\
\text { Memperlihatkan } \\
\text { pinggang keatas } \\
\text { dari subjek } \\
\text { Long Shot, } \\
\text { Foreground } \\
\text { Memperlihatkan } \\
\text { pinggang keatas } \\
\text { dari subjek } \\
\text { Medium Shot, } \\
\text { Group Shot } \\
\text { Memperlihatkan } \\
\text { pinggang keatas } \\
\text { dari subjek }\end{array}$ \\
\hline Denotasi & \multicolumn{2}{|c|}{$\begin{array}{l}\text { Yogja Hip Hop Foundation, } \\
\text { Marzuki Muhammad alias Kill } \\
\text { The DJ. Marzuki tampil } \\
\text { menyanyikan lagunyaRaminggir } \\
\text { Tabrak, Cinta dan teman- } \\
\text { temannya sedang menikmati dan } \\
\text { menari mengikuti lagu tersebut } \\
\text { dalam sebuah acara di jogja. Dj } \\
\text { menggunakan baju bertulisan } \\
\text { yogya dan lagu yang } \\
\text { dinyanyikan mengunakan } \\
\text { bahasa Jawa Tengah yang khas. }\end{array}$} \\
\hline Konotasi & \multicolumn{2}{|c|}{$\begin{array}{l}\text { Yogyakarta dikenal sebagai kota } \\
\text { yang memegang teguh budaya } \\
\text { tradisionalyang kental dengan } \\
\text { budaya kerajaan, seakan tidak } \\
\text { tersentuh oleh budaya modern. } \\
\text { Musik dan acara yang } \\
\text { ditampilkan bernuansa modern } \\
\text { tetapi masih menggunakan } \\
\text { bahasa daerah yang kental } \\
\text { terdapat kontradiksi antara nilai } \\
\text { budaya daerah dengan acara dan } \\
\text { musik yang ditampilkan hal } \\
\text { tersebut menggambarkan kota } \\
\text { Yogyakarta sebagai perpaduan } \\
\text { antara tradisional dan modern }\end{array}$} \\
\hline Mitos & \multicolumn{2}{|c|}{$\begin{array}{l}\text { Budaya Yogyakarta yang } \\
\text { tradisional dianggap kaku dan } \\
\text { tidak bisa menerima unsur-unsur } \\
\text { modern. Budaya kerajaan pada } \\
\text { akhirnya tidak bisa menutup } \\
\text { diri. Masyarakat Yogyakarta } \\
\text { sekarang sudah menerima unsur }\end{array}$} \\
\hline
\end{tabular}




\section{Scene}

Adegankedua yang dipilih adalah suasana kota yogyakarta di pusat kota dan pasar tradisional.

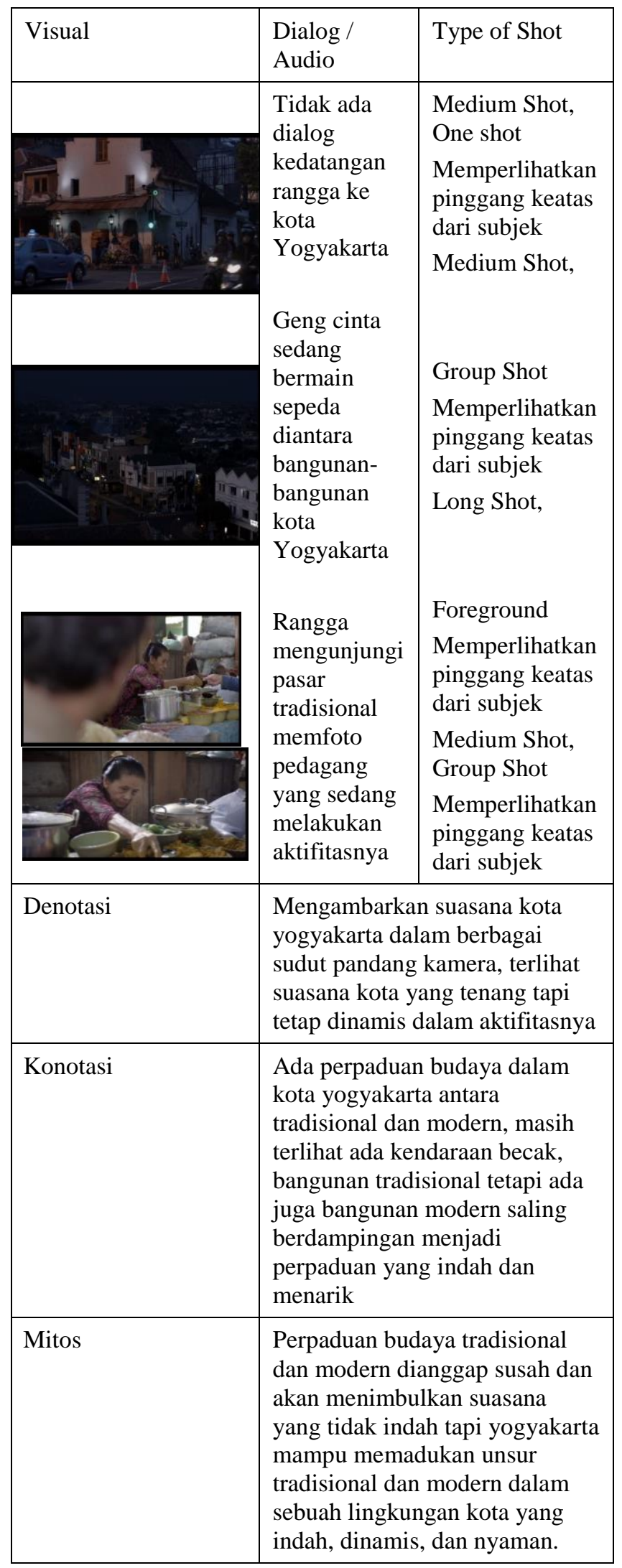

\section{Scene}

Adegan ketiga yang dipilih adalah galeri Eko Nugroho.

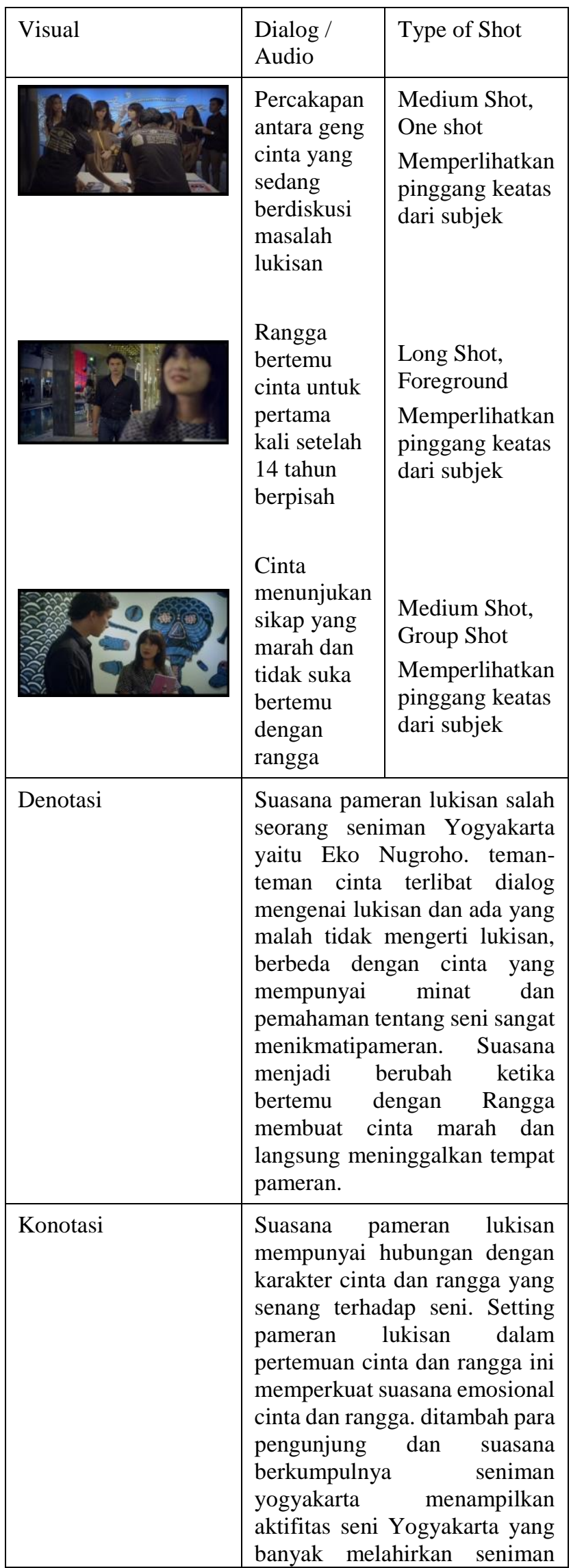




\begin{tabular}{|l|l|}
\hline & $\begin{array}{l}\text { bertaraf internasional salah } \\
\text { satunya Eko Nugroho. }\end{array}$ \\
\hline Mitos & $\begin{array}{l}\text { Seniman Yogyakarta } \\
\text { mempunyai lingkungan yang } \\
\text { mendukung dalam berkarya } \\
\text { mulai dari aktifitasnya sampai } \\
\text { pada apresiasi dari masyarakat } \\
\text { terhadap karya-karyanya. } \\
\text { Yogyakarta adalah tempat } \\
\text { berkumpul seniman dalam } \\
\text { mengembangkan } \\
\text { kreatifitasnya. }\end{array}$ \\
\hline
\end{tabular}

\section{Scene}

Adegan keempat yang dipilih adalah Rangga dan Cinta mengunjungi situs bersejarah Ratu

Boko.

\begin{tabular}{|c|c|c|}
\hline Visual & $\begin{array}{l}\text { Dialog / } \\
\text { Audio }\end{array}$ & Type of Shot \\
\hline$\sqrt{16}$ & $\begin{array}{l}\text { Rangga dan } \\
\text { Cinta } \\
\text { mengunjungi } \\
\text { tempat } \\
\text { favorit ayah } \\
\text { Rangga di } \\
\text { Yogyakarta } \\
\text { yaitu istana } \\
\text { Ratu Boko }\end{array}$ & $\begin{array}{l}\text { Medium Shot, } \\
\text { One shot } \\
\text { Memperlihatkan } \\
\text { pinggang keatas } \\
\text { dari subjek } \\
\text { Medium Shot, } \\
\text { Group Shot } \\
\text { Memperlihatkan } \\
\text { pinggang keatas } \\
\text { dari subjek } \\
\text { Long Shot, } \\
\text { Foreground } \\
\text { Memperlihatkan } \\
\text { pinggang keatas } \\
\text { dari subjek } \\
\text { Medium Shot, } \\
\text { Group Shot } \\
\text { Memperlihatkan } \\
\text { pinggang keatas } \\
\text { dari subjek }\end{array}$ \\
\hline Denotasi & \multicolumn{2}{|c|}{$\begin{array}{l}\text { Rangga dan Cinta mengunjungi } \\
\text { tempat bersejarah. Tempat yang } \\
\text { indah bekas peninggalan ratu } \\
\text { boko, mereke berjalan mengitari } \\
\text { reruntuhan bangunan mereka } \\
\text { terlibat dalam diskusi banyak hal } \\
\text { dari urusan politik, sejarah } \\
\text { bangunan sampai pada masalah } \\
\text { pribadi mereka. }\end{array}$} \\
\hline Konotasi & \multicolumn{2}{|c|}{$\begin{array}{l}\text { Setting disitus bersejarah Ratu } \\
\text { boko menguatkan karakter } \\
\text { tokohnya yang menyukai seni } \\
\text { dan sejarah. Yogyakarta sebagai } \\
\text { tempat lahirnya peradaban tinggi } \\
\text { dapat ditampilkan dalam bekas }\end{array}$} \\
\hline
\end{tabular}

\begin{tabular}{|l|l|}
\hline & $\begin{array}{l}\text { bangunan Ratu Boko. Peradaban } \\
\text { yang tinggi dalam } \\
\text { mengembangkan sebuah kota } \\
\text { yang ada penampungan air untuk } \\
\text { kebutuhan orang yang tinggal di } \\
\text { kota itu pada masa lalu }\end{array}$ \\
\hline Mitos & $\begin{array}{l}\text { Rangga sangat memahami } \\
\text { tempat-tempat di Yogyakarta } \\
\text { yang akan membuat Cinta } \\
\text { berkesan. Sejarah peradaban yang } \\
\text { tinggi di masa lalu membuat } \\
\text { Cinta terkesima. Yogyakarta } \\
\text { sebagai kota wisata kerajaan } \\
\text { ditampilkan dengan sangat } \\
\text { mendalam dalam adegan ini. }\end{array}$ \\
\hline
\end{tabular}

\section{Scene 1}

Adegankelima yang dipilihadalahlokasi di puthuk setumbu, klinik kopi, dan pertunjukan papermoon.

\begin{tabular}{|c|c|c|}
\hline Visual & $\begin{array}{l}\text { Dialog / } \\
\text { Audio }\end{array}$ & Type of Shot \\
\hline & $\begin{array}{l}\text { Rangga dan } \\
\text { Cinta } \\
\text { mengunjungi } \\
\text { puthuk } \\
\text { setumbu ada } \\
\text { bangunan } \\
\text { indah gereja } \\
\text { ayam yang } \\
\text { bisa melihat } \\
\text { borobudur } \\
\text { dan matahari } \\
\text { terbit } \\
\text { Rangga dan } \\
\text { cinta } \\
\text { mengunjungi } \\
\text { klinik kopi } \\
\text { yaitu sebuah } \\
\text { kedai kopi } \\
\text { yang unik } \\
\text { Rangga dan } \\
\text { Cinta } \\
\text { menonton } \\
\text { pertunjukan } \\
\text { papper moon } \\
\text { sebuah } \\
\text { pentas cerita } \\
\text { yang } \\
\text { ditampilkan } \\
\text { lewat } \\
\text { boneka bisu } \\
\text { tanpa suara }\end{array}$ & $\begin{array}{l}\text { Medium Shot, } \\
\text { One shot } \\
\text { Memperlihatkan } \\
\text { pinggang keatas } \\
\text { dari subjek } \\
\text { Medium Shot, } \\
\text { Group Shot } \\
\text { Memperlihatkan } \\
\text { pinggang keatas } \\
\text { dari subjek }\end{array}$ \\
\hline Denotasi & \multicolumn{2}{|c|}{$\begin{array}{l}\text { Rangga dan Cinta mengunjungi } \\
\text { lokasi wisata khas Yogyakarta } \\
\text { yang bukan peninggalan sejarah }\end{array}$} \\
\hline
\end{tabular}




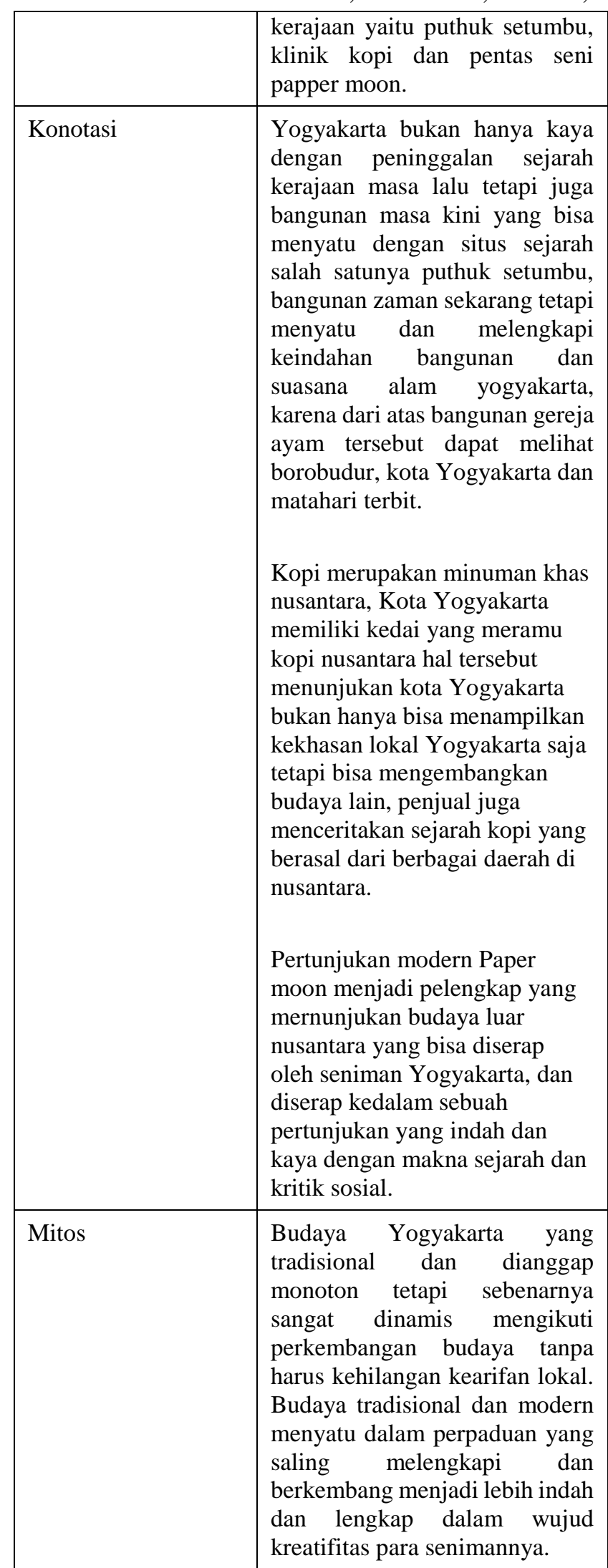

\section{SIMPULAN}

Setelah peneliti menganalisis data berupa rangkaian scene dalam film Ada Apa Dengan Cinta 2 untuk mencari makna denotasi, konotasi dan mitos yang dapat merepresentasikan Yogyakarta sebagai kota seni, maka peneliti merumuskan beberapa hal yaitu makna denotasi dalam penelitian ini adalah gambaran potret Yogyakarta sebagai kota seni, sehingga ada beberapa lokasi yang memperkuat emosional karakter tokoh utamanya yaitu seni modern yang diwakili dalam film ini adalah DJ pada hiburan malam, pertunjukan papermoon, pameran lukisan dan klinik kopi dilengkapi juga dengan wisata sejarah peninggalan kerajaan yaitu situs bersejarah Ratu Boko. Makna konotasi dalam penelitian ini adalah perpaduan budaya tradisonal dan modern yang saling melengkapi dan indah dalam kreatifitas para senimannya, tanpa harus kehilangan kearifan lokal yang ada di Yogyakarta. terlihat dari pertunjukan papermoon dan galeri lukisan Eko Nugroho. Mitosnya adalah Yogyakarta yang merupakan kota yang memegang teguh budaya tradisonal tetap terlihat dalam beberapa aktifitas masyarakatnya, budaya yang tertutup dan kaku tidak bisa meyerap budaya modern untuk kalangan orang tua dan bangsawan. Dalam film ini merepresentasikan Yogyakarta sebagai kota seni, perpaduan budaya tradisonal dan modern memperkuat karakter tokoh utamanya.

\section{DAFTAR PUSTAKA}

Ardianto, Elvinaro, Lukiati Komala \& Siti Karlinah. 2007. Komunikasi Massa: Suatu Pengantar (Edisi Revisi). Bandung: Simbiosa Rekatama Media. 
Biagi, Shirley. 2005. Media Impact: An Introduction to Mass Media 7th Edition. Canada: Thomson-Wadworth.

Budiman, Kris. 1999. Kosa Semiotika. Yogyakarta: LkiS.

Chandler, Daniel. 1999. Semiotics for Beginners. Wales: University of Wales.

Danesi, Marcel. 2010. Pengantar Memahami Semiotika Media. Yogyakarta: Jalasutra. . 2011. Pesan, Tanda, dan

Makna. Yogyakarta: Jalasutra.

Eriyanto. 2011. Analisis Wacana: Pengantar Analisis Teks Media. Yogyakarta: LKiS.

Fiske, John. 1990. Introduction to Communication Studies. London: Roudledge.

Moleong, Lexy J. 2000. Metode Penelitian Kualitatif. Bandung: PT. Remaja Rosdakarya.

Mulyana, Deddy. 2000. Ilmu Komunikasi:

Suatu Pengantar. Bandung: PT Remaja Rosdakarya. 2008. Komunikasi Efektif:

Suatu Pendekatan Lintasbudaya. Bandung: Remaja Rosdakarya.
Samovar, Larry A., Richard E Porter \& Edwin McDaniel. 2014. Komunikasi Lintas Budaya (Communication Between Cultures) Edisi ke-7. Jakarta: Salemba Humanika.

Sobur, Alex. 2001. Semiotika Komunikasi. Bandung: PT. Remaja Rosdakarya.

Sunardi, ST. 2002. Semiotika Negativa. Yogyakarta: Kanal.

Wibowo, Indiwan Seto Wahyu. 2011. Semiotika Komunikasi: Aplikasi Praktis Bagi Penelitian dan Skripsi Komunikasi. Jakarta: Mitra Wacana Media.

\section{Sumber lainnya}

http://www.kemendagri.go.id/pages/profildaerah/provinsi/detail/34/di-yogyakarta https://m.tempo.co/read/news/2016/05/06/1117 68823/aadc-2-ini-alasan-rangga-dan-cintadipertemukan-di-jogja https://indonesiana.tempo.co/read/9142/2014/0 2/12/samisidiq/ekspansi-budaya-lepaslandas-kebudayaan-indonesia 